\title{
Off-pump coronary artery bypass grafting in octogenarians
}

\author{
Shahzad G. Raja \\ Department of Cardiac Surgery, Harefield Hospital, London, UK \\ Correspondence to: Shahzad G. Raja, BSc, MBBS, MRCS, FRCS(C-Th). Department of Cardiac Surgery, Harefield Hospital, London, UK. \\ Email: drrajashahzad@hotmail.com.
}

\begin{abstract}
Enhanced life expectancy has confronted cardiac surgery with a rapidly growing population of octogenarians needing coronary artery bypass grafting (CABG). Octogenarians are deemed a high-risk patient population with increased postoperative morbidity and mortality following conventional CABG using cardiopulmonary bypass (CPB). In such patients reducing the invasiveness of the surgical procedure by avoiding $\mathrm{CPB}$ may be tried in an attempt to improve outcomes. The increasing performance of offpump coronary artery bypass (OPCAB) grafting within certain centers reflects surgeon preference to avoid the inherent risks of $\mathrm{CPB}$ and cardioplegic arrest including hemodilution, nonpulsatile arterial flow, global myocardial ischemia, atherosclerotic embolization from aortic manipulation, and systemic inflammatory response. Although OPCAB grafting is a well-established surgical myocardial revascularization strategy, its actual benefits in terms of morbidity and mortality remain questionable in the general population. In the higher risk octogenarian patients, however, there is a potential for more tangible clinical benefits when $\mathrm{CPB}$ is avoided. This review article provides an overview of the impact of OPCAB grafting on postoperative mortality and morbidity in octogenarians.
\end{abstract}

Keywords: Coronary artery bypass grafting (CABG); off-pump coronary artery bypass grafting; octogenarians; cardiopulmonary bypass (CPB)

Submitted Aug 05, 2016. Accepted for publication Aug 29, 2016.

doi: $10.21037 /$ jtd.2016.10.106

View this article at: http://dx.doi.org/10.21037/jtd.2016.10.106

\section{Introduction}

The global elderly population is expanding rapidly, particularly as longevity is also on the rise. In the United States, the population aged 65 and over is projected to almost double from 43.1 million in 2012 to 83.7 million by 2050 (1). The most rapid growth in numbers is for those who are very old ( $\geq 85$ years) (1). On a global scale, the population $\geq 85$ years is projected to increase $151 \%$ between 2005 and 2030, compared to the increase of only $104 \%$ in the population aged $\geq 65$ years and only $21 \%$ for the population under 65 (1).

Octogenarians tend to have higher rates of comorbid risk factors, which may result in more frequent and severe complications, and higher mortality rates (2). Specific cardiac risks in this patient group include aortic calcification, stiff vessels, diminished cardiovascular response to exercise, and intolerance of anemia. Additional age- related changes affect performance and physiologic reserve of the pulmonary, renal, and nervous systems as well (3). Nevertheless, surgical outcomes in this age group have been encouraging (4-8).

The merits and indications of off-pump coronary artery bypass (OPCAB) grafting continue to be debated as the body of evidence examining this technique grows. The current best available evidence from meta-analyses suggests that compared with conventional coronary artery bypass grafting (CABG) using cardiopulmonary bypass (CPB), OPCAB grafting significantly reduces stroke, renal failure, duration of ventilation, atrial fibrillation, transfusion requirements and postoperative length of stay (9-14). Conversely, some randomized controlled trials have been unable to show such benefits (15-21), or have questioned the long-term benefit of OPCAB grafting in terms of graft patency(16,18-21).

Irrespective of the ongoing debate about benefits of 
OPCAB grafting in low and intermediate risk patients, there is abundant evidence to suggest that OPCAB grafting should be preferentially offered to high-risk patients including octogenarians as there is a potential for more tangible clinical benefits when CPB is avoided $(22,23)$. This review article provides an overview of the impact of OPCAB grafting on postoperative mortality and morbidity in octogenarians.

\section{Methods}

\section{Search methodology}

English scientific literature was reviewed primarily by searching MEDLINE from 1966 to May 2016 using PubMed interface (24). The search strategy used was ("coronary artery bypass, off-pump" [MeSH Terms] OR ("coronary"[All Fields] AND "artery"[All Fields] AND "bypass"[All Fields] AND “off-pump”[All Fields]) OR “offpump coronary artery bypass"[All Fields] OR ("off”[All Fields] AND "pump"[All Fields] AND "coronary"[All Fields] AND "artery"[All Fields] AND "bypass"[All Fields]) OR “off pump coronary artery bypass"[All Fields]) AND ("transplantation" [Subheading] OR "transplantation"[All Fields] OR "grafting”[All Fields] OR "transplantation" [MeSH Terms] OR "grafting"[All Fields]) AND ("aged, 80 and over" [MeSH Terms] OR " 80 and over aged"[All Fields] OR “octogenarians"[All Fields]). The 'related articles' function was used to broaden the search and all abstracts, studies and citations scanned were reviewed. The reference lists of articles found through these searches were also reviewed for relevant articles. In addition, EMBASE, Cochrane Controlled Trials Register, Cochrane Database of Systematic Reviews, Database of Abstracts of Reviews of Effects, Science Citation Index, Current Contents, and International Network of Agencies for Health Technology Assessment databases were searched from the date of their inception to the last week of May 2016.

The search was performed in stages so as to achieve the search strategy with a high sensitivity (meaning that it has the highest likelihood of retrieving all relevant papers). Similar search terms were combined using the Boolean operator 'OR' to find all abstracts that contained information about a particular search term. These individual terms were then combined using the Boolean operator 'AND' to find papers that contained information on all the search terms. This is a well-recognized method for performing sensitive searches and has been described in detail in the British Medical Fournal (25).

\section{Inclusion \& exclusion criteria}

All studies comparing OPCAB grafting with conventional CABG on $\mathrm{CPB}$ using cardioplegic arrest, recruiting octogenarian patients undergoing single or multiple vessel bypass, and reporting mortality or morbidity (organ dysfunction) as outcome of interest were included. Studies reporting on outcomes of hybrid (i.e., OPCAB grafting plus balloon angioplasty) procedures, robotically assisted surgery or using circulatory assist devices were excluded.

\section{Data extraction and validation of the studies}

The papers found by the search strategy were then appraised. The appraisal of each paper was performed in a structured format, using critical appraisal checklists. These are widely available in several formats and aid in assessing the paper for methodological and analytical soundness and help uncover any significant methodological flaws (26). The following information was extracted from each study: first author, year of publication, study population characteristics, number of patients operated on with each technique and key outcomes. The aforementioned search methodology and study selection strategy has been previously described (27).

\section{Results}

A total of 614 citations were retrieved and reviewed using the search strategy. After exclusion of case reports, review articles, case series, and editorials, 19 citations were selected for review of full text articles. Following exclusion of one article where the full text was in Japanese (28), 18 articles were deemed suitable and met the inclusion criteria listed above. All 18 studies were retrospective studies (2,29-45). Five studies $(38,40,42-44)$ presented propensity-matched comparison of the 2 cohorts. One presented the analysis of the Nationwide Inpatient Sample database from 2005 to 2010 (39), whereas another reported data from the State of Virginia database for the period 2003 to 2008 (44). The remaining studies were from single centers. The detailed review process is outlined in Figure 1 and study results in Table 1.

The selected studies suggested that rates of early mortality, new-onset renal failure, atrial fibrillation, 


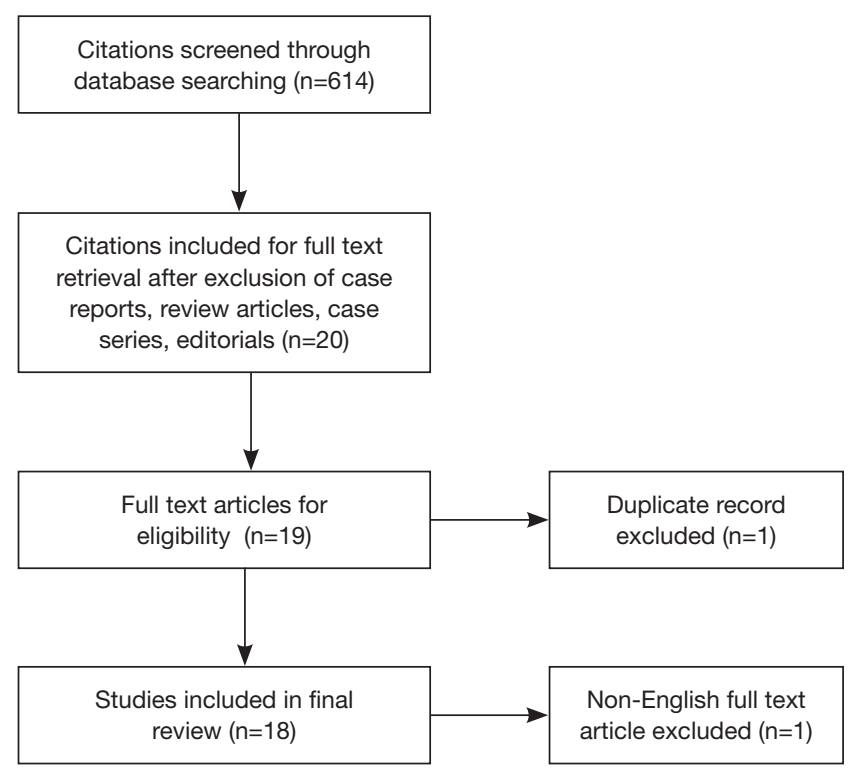

Figure 1 Flow chart depicting study selection for the review.

and myocardial infarction were comparable (Table 1). Respiratory failure and stroke rates were higher in octogenarians that had CABG with the aid of CPB (Table 1). There was wide variation in the number of grafts performed in each group amongst the selected studies with only four studies $(34,35,38,40)$ reporting a similar number of grafts in both cohorts. Late survival (follow-up period ranging from 2-10 years) was reported by only 4 of the 18 studies $(31,37,40,42)$ and was comparable. A meta-analysis of 16 of the 18 studies included in this review reported similar findings (46).

\section{Discussion}

Cardiac surgery in octogenarians has risen steadily since the 1980s. The octogenarians are now the fastest growing population in Western countries, and the number of octogenarians with coronary artery disease potentially eligible for surgery is expected to increase (47).

Conventional CABG with the aid of CPB and cardioplegic arrest has, for many years, been regarded the "gold standard" in coronary revascularization (43). However, during the last 10 to 15 years, OPCAB has emerged as a valid alternative. This status of OPCAB is based on the perception that avoiding injurious effects of the CPB improves outcomes and possibly decreases resource utilization and costs (48). High-risk patients including the octogenarians are particularly vulnerable to organ dysfunction due to the deleterious effects of CPB (49). There is convincing evidence from observational studies, propensity score analyses, and randomized controlled trials, that OPCAB is associated with risk reduction for stroke and acute kidney injury as well as reduction in transfusion and inotrope requirements, ventilation time, intensive care unit and hospital stays $(9,13)$. Hence, there is a logical argument to offer $\mathrm{OPCAB}$ surgery preferentially to octogenarians because decline of neurocognitive functions, delirium, stroke, increased length of stay, and renal failure are common complications more frequently encountered in this patient population $(45,50)$.

Acute postoperative neurological events considerably affect the outcome of cardiac surgery in octogenarians (50). There is also a direct relationship between acute postoperative neurological events and operative mortality. Neurological events also increase the tendency to develop respiratory complications, and prolong hospital stay by slowing patient recovery and ambulation (50,51). Despite multifactorial pathogenesis of cerebral injury and cognitive dysfunction after cardiac surgery, there is increasing evidence that diffuse ischemic cerebral injury is caused by multiple microemboli arising from the ascending aorta, the heart chambers, or the bypass circuit (52). Elimination of CPB and adoption of the aortic "no touch" technique, which avoids intraoperative atheromatous embolization from the atherosclerotic aorta into the cerebral circulation, are associated with improved neurologic outcomes (53). The current best available evidence albeit from retrospective studies confirms the beneficial impact of OPCAB in improving neurological outcomes in octogenarians (Table 1).

Postoperative pulmonary dysfunction is a significant cause of morbidity after CPB-assisted surgery (53). The occurrence of pulmonary derangement after cardiac surgery is thought to be multifactorial. In addition, to disruption of chest wall mechanics, it is well recognized that $\mathrm{CPB}$ induced inflammatory response produces increased pulmonary endothelial permeability, parenchymal damage, and changes in the composition of alveolar surfactant $(54,55)$. It can be hypothesized that avoiding CPB should reduce postoperative pulmonary dysfunction due to absence of the CPB-induced systemic inflammatory response. This benefit is more likely to be seen in the octogenarian population and is confirmed by the current best available evidence (46).

Currently, the evidence comparing impact of OPCAB on postoperative complications in octogenarians fails to show an impressive advantage of avoiding $\mathrm{CPB}$ other than reduction in respiratory failure and stroke 


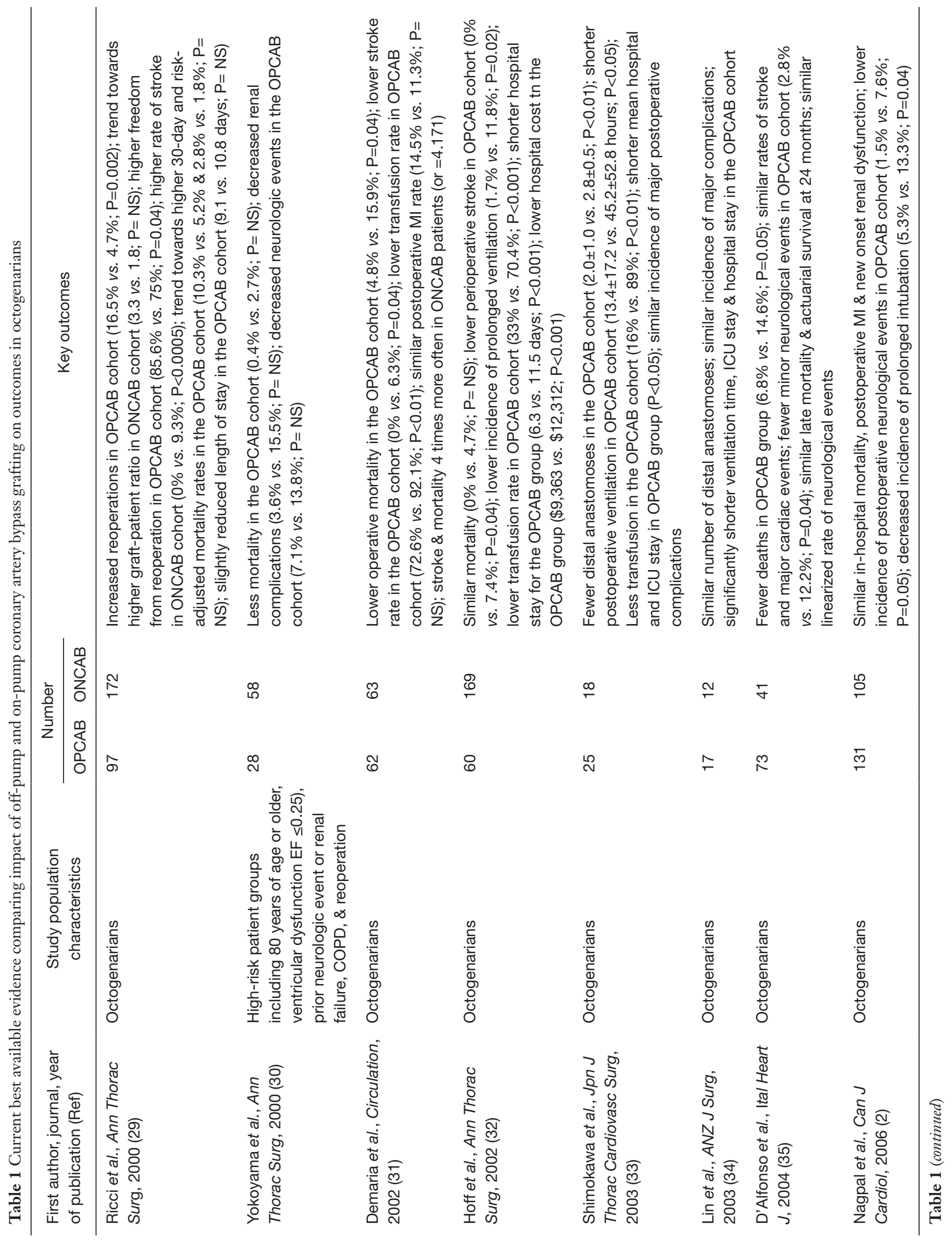




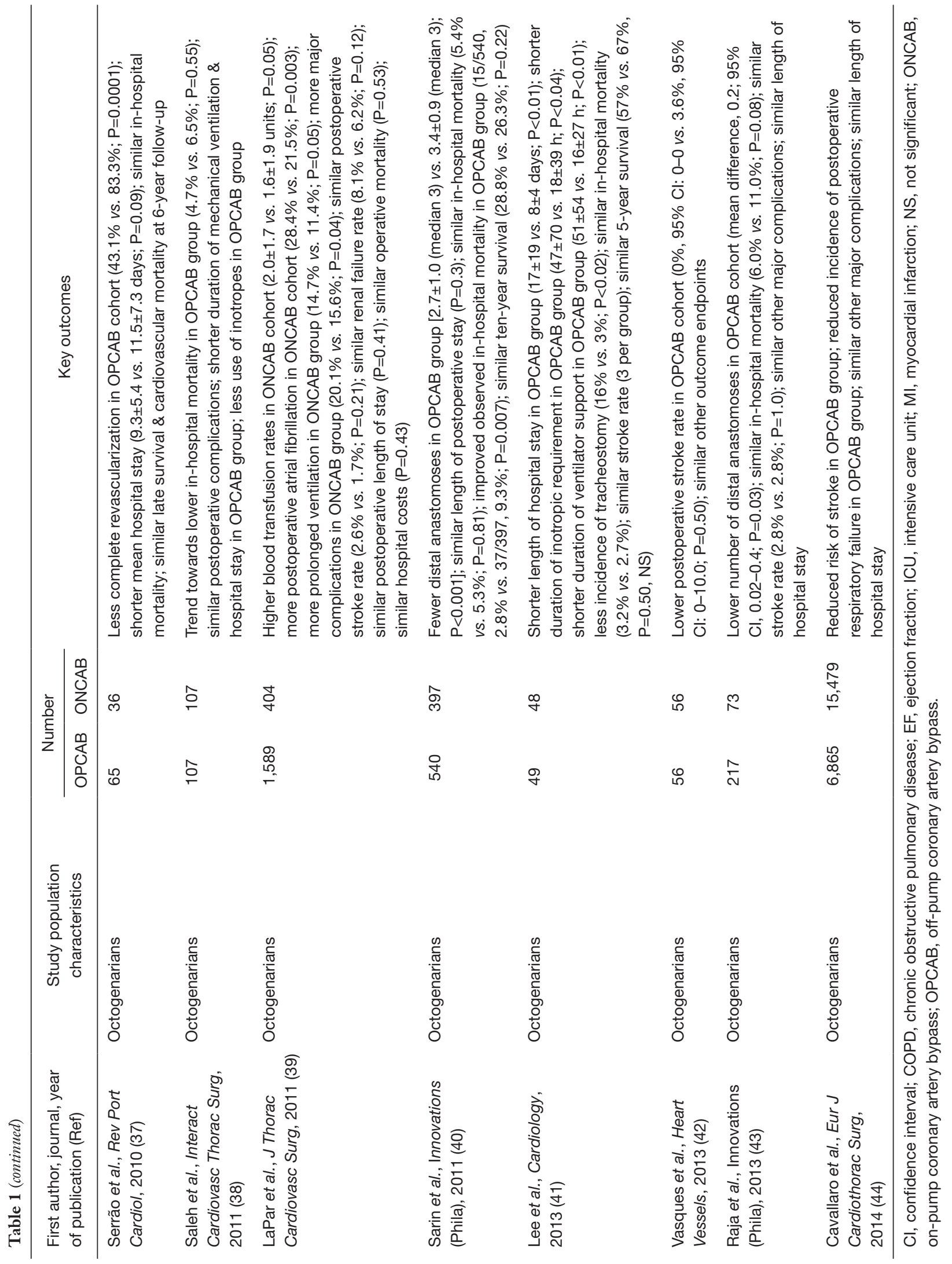


rates. However, an argument for offering OPCAB to octogenarians preferentially could be based on the assumption that reduction of neurological derangements including stroke and respiratory complications results in a shorter postoperative period of intensive care unit stay and hospital stay along with lesser use of inotropes and blood product usage. Such findings although apparently insignificant, may translate into substantial savings in this group of patients with a higher-level of resource utilization perioperatively (56).

Survival, mortality, morbidity, complication rate, symptom recurrence, and need for re-interventions, well-recognized objective outcome measure, have long been used as benchmarks for successful cardiac surgery, including CABG. In addition to these benchmarks, acquired improvement by cardiac surgery in subjectively experienced health-related quality of life (HRQoL) has gained importance during the last decade in cardiac surgical research. If an increasing proportion of adult patients referred for CABG are elderly, octogenarians or even nonagenarians, the acquired HRQoL benefit from bypass surgery should be considered to be at least as important an outcome measure as potentially marginal improvement in life expectancy or longevity alone (57). It is extremely important that informed discussion of treatment options, potential for discharge to a nursing care facility, and quality of life expectations should precede a decision to undertake cardiac surgery in octogenarians (56).

The available evidence on the subject is fraught with limitations. Majority of the studies are prone to a degree of selection bias due to their retrospective, single center observational nature. The relatively long time period these studies cover and their retrospective nature may carry unidentified variables affecting outcomes that remain unaccounted for in the final analysis in all of these studies. Furthermore, size of the study populations in most studies published to date remains small predominantly as the population size for octogenarians remains relatively small when compared to the total volume of most surgical units. Last but not the least, there is a need for further studies with longer follow-up as majority of the studies report short-term or early outcomes.

\section{Conclusions}

The decision to offer surgery is complex in octogenarian patients and one must take into account multiple factors, such as the lack of conformity between physiological age and chronological age, the quality of life, and the riskbenefit ratio. Furthermore, with consistent and careful application of modern techniques and clinical practices the risk of death from a cardiac operation in octogenarians can be reduced to that of younger patients. It is therefore not unreasonable to hypothesize that $\mathrm{OPCAB}$, due to its less invasive nature compared to conventional $\mathrm{CABG}$, appears an attractive option to reduce procedure-specific mortality and morbidity in the octogenarian patients. However, current retrospective studies with small numbers, examining the impact of OPCAB on early mortality and morbidity in octogenarians, have failed to prove overwhelming superiority of one technique over the other. At present it can be safely concluded that both on-pump and offpump CABG are reasonable revascularization strategies in octogenarians. The decision to offer one or the other strategy preferentially must be guided predominantly by the patient's risk profile reiterating the importance of careful patient selection and individualized treatment decisions.

\section{Acknowledgements}

None.

\section{Footnote}

Conflicts of Interest: The author has no conflicts of interest to declare.

\section{References}

1. Forman DE, Alexander K, Brindis RG, et al. Improved Cardiovascular Disease Outcomes in Older Adults. F1000Res 2016;5. pii: F1000 Faculty Rev-112.

2. Nagpal AD, Bhatnagar G, Cutrara CA, et al. Early outcomes of coronary artery bypass with and without cardiopulmonary bypass in octogenarians. Can J Cardiol 2006;22:849-53.

3. Oskvig RM. Special problems in the elderly. Chest 1999;115:158S-164S.

4. Baskett R, Buth K, Ghali W, et al. Outcomes in octogenarians undergoing coronary artery bypass grafting. CMAJ 2005;172:1183-6.

5. Beauford RB, Goldstein DJ, Sardari FF, et al. Multivessel off-pump revascularization in octogenarians: early and midterm outcomes. Ann Thorac Surg 2003;76:12-7; 
discussion 17.

6. Smith KM, Lamy A, Arthur HM, et al. Outcomes and costs of coronary artery bypass grafting: comparison between octogenarians and septuagenarians at a tertiary care centre. CMAJ 2001;165:759-64.

7. Alexander KP, Anstrom KJ, Muhlbaier LH, et al. Outcomes of cardiac surgery in patients $>$ or $=80$ years: results from the National Cardiovascular Network. J Am Coll Cardiol 2000;35:731-8.

8. Fruitman DS, MacDougall CE, Ross DB. Cardiac surgery in octogenarians: can elderly patients benefit? Quality of life after cardiac surgery. Ann Thorac Surg 1999;68:2129-35.

9. Wijeysundera DN, Beattie WS, Djaiani G, et al. Offpump coronary artery surgery for reducing mortality and morbidity: meta-analysis of randomized and observational studies. J Am Coll Cardiol 2005;46:872-82.

10. Møller CH, Penninga L, Wetterslev J, et al. Clinical outcomes in randomized trials of off- vs. on-pump coronary artery bypass surgery: systematic review with meta-analyses and trial sequential analyses. Eur Heart J 2008;29:2601-16.

11. Møller CH, Penninga L, Wetterslev J, et al. Off-pump versus on-pump coronary artery bypass grafting for ischaemic heart disease. Cochrane Database Syst Rev 2012;(3):CD007224.

12. Feng ZZ, Shi J, Zhao XW, et al. Meta-analysis of on-pump and off-pump coronary arterial revascularization. Ann Thorac Surg 2009;87:757-65.

13. Godinho AS, Alves AS, Pereira AJ, et al. On-pump versus off-pump coronary-artery bypass surgery: a meta-analysis. Arq Bras Cardiol 2012;98:87-94.

14. Kuss O, von Salviati B, Börgermann J. Off-pump versus on-pump coronary artery bypass grafting: a systematic review and meta-analysis of propensity score analyses. J Thorac Cardiovasc Surg 2010;140:829-35, 835.e1-13.

15. Légaré JF, Buth KJ, King S, et al. Coronary bypass surgery performed off pump does not result in lower in-hospital morbidity than coronary artery bypass grafting performed on pump. Circulation 2004;109:887-92.

16. Shroyer AL, Grover FL, Hattler B, et al. On-pump versus off-pump coronary-artery bypass surgery. N Engl J Med 2009;361:1827-37.

17. Møller CH, Perko MJ, Lund JT, et al. No major differences in 30-day outcomes in high-risk patients randomized to off-pump versus on-pump coronary bypass surgery: the best bypass surgery trial. Circulation
2010;121:498-504.

18. Houlind K, Fenger-Grøn M, Holme SJ, et al. Graft patency after off-pump coronary artery bypass surgery is inferior even with identical heparinization protocols: results from the Danish On-pump Versus Off-pump Randomization Study (DOORS). J Thorac Cardiovasc Surg 2014;148:1812-1819.e2.

19. Lamy A, Devereaux PJ, Prabhakaran D, et al. Effects of off-pump and on-pump coronary-artery bypass grafting at 1 year. N Engl J Med 2013;368:1179-88.

20. Diegeler A, Börgermann J, Kappert U, et al. Off-pump versus on-pump coronary-artery bypass grafting in elderly patients. N Engl J Med 2013;368:1189-98.

21. Sousa Uva M, Cavaco S, Oliveira AG, et al. Early graft patency after off-pump and on-pump coronary bypass surgery: a prospective randomized study. Eur Heart J 2010;31:2492-9.

22. Kowalewski M, Pawliszak W, Malvindi PG, et al. Offpump coronary artery bypass grafting improves short-term outcomes in high-risk patients compared with on-pump coronary artery bypass grafting: Meta-analysis. J Thorac Cardiovasc Surg 2016;151:60-77.e1-58.

23. Lemma MG, Coscioni E, Tritto FP, et al. On-pump versus off-pump coronary artery bypass surgery in high-risk patients: operative results of a prospective randomized trial (on-off study). J Thorac Cardiovasc Surg 2012;143:625-31.

24. Motschall E, Falck-Ytter Y. Searching the MEDLINE literature database through PubMed: a short guide. Onkologie 2005;28:517-22.

25. Greenhalgh T. How to read a paper. The Medline database. BMJ 1997;315:180-3.

26. Mackway-Jones K, Carley CD, Morton RJ. Best BETs Critical Appraisal Worksheets [Cited 1 July 2016]. Available online: http://bestbets.org/links/BET-CAworksheets.php

27. Raja SG, Dreyfus GD. Impact of off-pump coronary artery bypass surgery on postoperative renal dysfunction: current best available evidence. Nephrology (Carlton) 2006;11:269-73.

28. Matsumoto Y, Endo M, Kasashima F, et al. Off-pump coronary artery bypass grafting for octogenarians with acute coronary syndrome. Kyobu Geka 2003;56:682-7.

29. Ricci M, Karamanoukian HL, Abraham R, et al. Stroke in octogenarians undergoing coronary artery surgery with and without cardiopulmonary bypass. Ann Thorac Surg 2000;69:1471-5.

30. Yokoyama T, Baumgartner FJ, Gheissari A, et al. Off- 
pump versus on-pump coronary bypass in high-risk subgroups. Ann Thorac Surg 2000;70:1546-50.

31. Demaria RG, Carrier M, Fortier S, et al. Reduced mortality and strokes with off-pump coronary artery bypass grafting surgery in octogenarians. Circulation 2002;106:15-10.

32. Hoff SJ, Ball SK, Coltharp WH, et al. Coronary artery bypass in patients 80 years and over: is off-pump the operation of choice? Ann Thorac Surg 2002;74:S1340-3.

33. Shimokawa T, Minato N, Yamada N, et al. Off-pump coronary artery bypass grafting in octogenarians. Jpn J Thorac Cardiovasc Surg 2003;51:86-90.

34. Lin CY, Hong GJ, Lee KC, et al. Off-pump technique in coronary artery bypass grafting in elderly patients. ANZ J Surg 2003;73:473-6.

35. D'Alfonso A, Mariani MA, Amerini A, et al. Off-pump coronary surgery improves in-hospital and early outcomes in octogenarians. Ital Heart J 2004;5:197-204.

36. Tugtekin S, Kappert U, Alexiou K, et al. Coronary artery bypass grafting in octogenarians--outcome with and without extracorporeal circulation. Thorac Cardiovasc Surg 2007;5 5:407-11.

37. Serrão M, Graça F, Rodrigues R, et al. Coronary artery bypass grafting in octogenarians: long-term results. Rev Port Cardiol 2010;29:989-98.

38. Saleh HZ, Shaw M, Fabri BM, et al. Does avoidance of cardiopulmonary bypass confer any benefits in octogenarians undergoing coronary surgery? Interact Cardiovasc Thorac Surg 2011;12:435-9.

39. LaPar DJ, Bhamidipati CM, Reece TB, et al. Is off-pump coronary artery bypass grafting superior to conventional bypass in octogenarians? J Thorac Cardiovasc Surg 2011;141:81-90.

40. Sarin EL, Kayatta MO, Kilgo P, et al. Short- and longterm outcomes in octogenarian patients undergoing offpump coronary artery bypass grafting compared with onpump coronary artery bypass grafting. Innovations (Phila) 2011;6:110-5.

41. Lee DC, Ramirez SA, Bacchetta $M$, et al. Off-pump versus on-pump coronary artery bypass grafting in octogenarians: comparison of short-term outcomes and long-term survival. Cardiology 2013;125:164-9.

42. Vasques F, Rainio A, Heikkinen J, et al. Off-pump versus on-pump coronary artery bypass surgery in patients aged 80 years and older: institutional results and meta-analysis. Heart Vessels 2013;28:46-56.

43. Raja SG, Shah J, Navaratnarajah M, et al. Outcomes and predictors of mortality and stroke after on-pump and offpump coronary artery bypass surgery in octogenarians. Innovations (Phila) 2013;8:269-75.

44. Cavallaro P, Itagaki S, Seigerman M, et al. Operative mortality and stroke after on-pump vs off-pump surgery in high-risk patients: an analysis of 83,914 coronary bypass operations. Eur J Cardiothorac Surg 2014;45:159-64.

45. Spunda R, Valek M, Salmay M, et al. Differential impact on acute kidney injury incidence between on- and off pump coronary artery bypass grafting in octogenarians. Biomed Pap Med Fac Univ Palacky Olomouc Czech Repub 2015;159:449-54.

46. Altarabsheh SE, Deo SV, Rababa'h AM, et al. Offpump coronary artery bypass reduces early stroke in octogenarians: a meta-analysis of 18,000 patients. Ann Thorac Surg 2015;99:1568-75.

47. Speziale G, Nasso G, Barattoni MC, et al. Short-term and long-term results of cardiac surgery in elderly and very elderly patients. J Thorac Cardiovasc Surg 2011;141:72531, 731.e1.

48. Raja SG, Dreyfus GD. Impact of off-pump coronary artery bypass surgery on post-operative pulmonary dysfunction: current best available evidence. Ann Card Anaesth 2006;9:17-24.

49. Marti L, Cervera C, Filella X, et al. Cytokine-release patterns in elderly patients with systemic inflammatory response syndrome. Gerontology 2007;53:239-44.

50. Ngaage DL, Cowen ME, Griffin S, et al. Early neurological complications after coronary artery bypass grafting and valve surgery in octogenarians. Eur J Cardiothorac Surg 2008;33:653-9.

51. Akins CW, Daggett WM, Vlahakes GJ, et al. Cardiac operations in patients 80 years old and older. Ann Thorac Surg 1997;64:606-14; discussion 614-5.

52. Knipp SC, Matatko N, Wilhelm H, et al. Evaluation of brain injury after coronary artery bypass grafting. A prospective study using neuropsychological assessment and diffusion-weighted magnetic resonance imaging. Eur J Cardiothorac Surg 2004;25:791-800.

53. Leacche M, Carrier M, Bouchard D, et al. Improving neurologic outcome in off-pump surgery: the "no touch" technique. Heart Surg Forum 2003;6:169-75.

54. Raja SG. Pump or no pump for coronary artery bypass: current best available evidence. Tex Heart Inst J 2005;32:489-501.

55. McGowan FX Jr, Ikegami M, del Nido PJ, et al. Cardiopulmonary bypass significantly reduces surfactant 
activity in children. J Thorac Cardiovasc Surg 1993;106:968-77.

56. Raja SG, Husain M, Chowdhury S. Octogenarians and coronary artery bypass grafting: current outcomes, concerns and caution. Interact Cardiovasc Thorac Surg
2011;12:439-40.

57. Jokinen JJ, Hippeläinen MJ, Turpeinen AK, et al. Healthrelated quality of life after coronary artery bypass grafting: a review of randomized controlled trials. J Card Surg 2010;25:309-17.

Cite this article as: Raja SG. Off-pump coronary artery bypass grafting in octogenarians. J Thorac Dis 2016;8(Suppl 10):S799S807. doi: $10.21037 /$ jtd.2016.10.106 